\title{
Service quality assessment of public transport and the implication role of demographic characteristics
}

\begin{abstract}
Purpose

This paper first proposes scales to evaluate customers' perceived service quality in public transport then identify the demographic characteristics factors that may influence customer perceived service quality and as well as to identify any customers' perceptions differences between the subcategories.

\section{Design/methodology/approach}

Manager interview and random sampling method were used to survey 288 consumers of buses public transport. Exploratory and confirmatory factor analyses were used to confirm the scale validity. Thereafter, Structural Equation Modeling, Mann-Whitney U and Kruskal-Wallis tests were used to asses the causal paths and the service quality perceptions differences among the subgroups.
\end{abstract}

\section{Findings}

The three dimensions of functional, convenience and physical environment quality were confirmed as underlying factors to assess customer perceived quality in public transport setting. Age and owning a driving license are factors that directly and positively affect service quality whereas education was negatively related to perceived quality. In contrast, the relationships between being a car user, gender and perceived quality were not supported. The results also showed that younger commuter appears to have lower perceptions of service quality as compared to adults. However, the current study does suggest that people with university education and above may be a better audience for advertising appeals focusing on one of these three significant dimensions of service quality.

\section{Originality/ value}

This study adds theoretical knowledge on how to assess opinions accurately of customers' perception of service quality in public transport services as well as to provide good insight on the direct role of demographic characteristics on customers' perceived service quality.

Keywords: Service quality, Age, Education, Driving license, Public transport service, Scale assessment

Article Classification: Research paper

Public Transport Classification: $\mathrm{H} 40$ 


\section{Introduction}

In the last thirty years, the economic globalization has fostered the ongoing process of residential suburbanization, employment decentralization and the increase in household revenue. All these factors in turn have spawned a pattern of travel that is more suited to the private car than to public transport. Undeniably, the changes observed in urban travel nowadays can be summarized by a growing number of motorized trips as well as an increase in the use of the private car (Hensher, 2003; Litman 2008; Cipriani et al., 2012; Schoettle and Sivak, 2014). In order to reverse this trend, some government and local authorities are now trying to implement actions that could contribute to the generation of positive user's attitudes to public transport (Martin et al., 2012).

According to Matas, (2004), the declining trend in public transport ridership can be reversed through an active public transport policy based on low cost travel passes and most importantly improvements in the quality of service offered. In this respect, some researchers have examined whether quality improvements have effects on satisfaction with public transport services and frequency of perceived negative critical incidents (Friman, 2004; Eboli and Mazzulla, 2010). Surprisingly, one of the most important findings of these studies is that the satisfaction people experience when using public transport services is influenced by quality improvements only to a very limited extent. Thus, prompting calls to understand "where" a public transport service must efficiently allocate resources to improve the service of quality offer and thus differentiate itself from its competitors.

Moreover, it was evidenced and generally accepted that the delivery of superior service quality in the retail sector is a vital tactic for success and business survival. With the economic globalization, even the public sector organizations have come under a growing pressure to deliver superior service quality. Yet, customer needs and expectations are different when it comes to governmental services and their quality requirements. Given that service quality practices in public sector organizations are slow and the outcomes are harder to measure (Ramseok-Munhurrun et al., 2010). Besides, there is a lack of freedom to act in an arbitrary way; more scrutiny from the public and press in addition to the pervasive influence of politics and a requirement for decisions to be based on law (Teicher et al., 2002). These distinction roles suggest vastly different kinds of expectations and accountability that may call for different decision making practices (Nutt, 2006).

Despite the debate, some authors have frequently emphasized the need to examine ways to increase customers' acquisition decision related to perceived service quality (Yaya et al., 2014). Obviously, understanding these antecedents can help service provider to gain competitive advantages by implementing specific strategies to increase their service quality offer. Particularly in public transport where service quality is a matter of the greatest importance because an improvement of quality levels can attract further users (Eboli \& Mazzulla, 2008). Moreover, previous researchers have demonstrated that delivery of higher levels of service quality reduces customers' perceptions of the potential benefits of alternative competitors, enhances repurchase intentions, contribute to the market share and return on investment (Parasuraman et al., 1988; Brady and Cronin, 2001; Karatepe et al., 2005). In addition, higher service quality results in customer satisfaction and loyalty, greater willingness to recommend to someone else, reduction in customer complaints, and improvement of customer retention (Hensheret al., 2003; 
Ladhari et al., 2009; Marimon et al., 2012; Yaya et al., 2013). Furthermore, even though a substantial amount of research on service quality can be found in the marketing literature, little attention has been paid to the influence of some demographic characteristics such as gender, education, age etc. on the construct of perceived service quality.

Against this background, the objectives of this study are threefold: first, to provide based on management interview and on up-to-date literature review the most comprehensive customer service quality assessment of public transport. Second, to identify demographic characteristics (gender, age, education, driving license and car user) that may influence customer perception service quality of public transport and finally, to categorize if there is any differences in term of service quality perception among the demographic characteristic groups.

This paper is structured as follows: After this introduction, the second section presents a review of literature, the conceptual framework and research hypotheses. Thereafter, the methodology used is described in the third section. Subsequently, the results are presented in the fourth section. Finally, the paper ends with the conclusion and management implications.

\section{Literature review}

\subsection{Service quality assessment in public transport}

Service quality has been conceptualized and defined as the outcome measure of the gap between customers' expected performance of service offered and its perceptions of the level of service received (Parasuraman et al., 1998). In general, the concepts of service quality are fundamental to successful business because they are crucial to costumers' decisions making (Yaya et al, 2011). Despite the phenomenal growth of the service sector, the results of existing studies on service quality suggest that the definitions and perceptions of service quality are quite diverse (e.g. Grönroos, 1984; Parasuraman et al., 1998; Brady and Cronin, 2001; Karatepe et al., 2005). Particularly in the public transport services they do not seem to fit any single existing quality model (e.g. Hu et al., 2006; Hensheret al., 2003; Eboli \& Mazzulla, 2008). This is probably due because of the difficulties involved in delimiting and measuring the construct. Given that unlike goods quality, which can be measured with some objectivity, service quality is abstract and elusive. The unique features of services such as inseparability of production and consumption, intangibility, and heterogeneity make measurement of quality a very complex issue (Karatepe et al., 2005).

Nonetheless, early research groundwork on service quality was based the disconfirmation paradigm and two schools of thought dominate the extant literature. In adapting the disconfirmation paradigm the Nordic school proposed two service quality dimensions: the functional quality which identified how the service is delivered and the technical quality that represents the outcome of the service (Grönroos, 1984). On the other hand the American school also divided the quality construct into different dimensions and comprehend customers' experiences such with the Tangibles, Reliability, Responsiveness, Assurance and Empathy that in turn served a common them represented by SERVQUAL. By using SERVQUAL as a modifier, Brady and Cronin, (2001) argued that service quality constructs conforms to the structure of a third order factor model 
including, interaction quality, physical environment quality, and outcome quality. Overall, it is generally accepted that all these models have contributed to better understand the service quality concept. However, there are still two important issues that are matters of debate. The first relates to the debate of whether service quality must be defined following the Scandinavian or the American conceptualization. The existing literature point toward that the SERVQUAL (American school) is the mostly used in the literature.

The second issue is that although there has been considerable progress as to how service quality should be assess, the applicability of a generic scale for measuring service quality in all settings has been questioned (Yaya et al., 2012). Given that many of the generic SERVQUAL items just do not apply in any specific context, some managers and researchers are often forced to radically modify the scale items (Ladhari et al., 2009). Drawing on that Karatepe et al., (2005) argued that instead of taking an existing instrument and trying to fit it to the context, a better approach is to develop an instrument specifically for the focal service. Given that, the more specific the scale items are in a service quality instrument and the more applicable they are to managers own contextual circumstance, the better the information collected are useful. For these reasons, many techniques for measuring service quality and defining the importance of service quality attributes and global satisfaction on public transport have been proposed in the literature.

For example, Ramseook-Munhurrun et al., (2010) have used and adapted the generic model of SERVQUAL to evaluate how closely customer expectations of service and front line employees perceptions of customer expectations match. The key finding of the study is that front line employees' perceptions should focus on those dimensions which receive lowest ratings and attributes with high gap scores. Moreover, Eboli \& Mazzulla, (2008) used a stated preference experiment to provide a way to measure service quality in public transport based on convenient students' sample. The authors concluded that the dimensions of quality viewed from a customer's perspective are complex and perceptions about qualitative characteristics of service are very different among users of public transport. Build on earlier research by the authors, Hensheret al., (2003) proposed service attributes to calculate an overall service quality index. They argued that their propose service quality index can be used to investigate ways of quantifying service quality, calculate the satisfaction associated with existing service levels and compare the levels within and between bus operators.

In addition, Beirao and Sarsfield-Cabral (2007) proposed a qualitative study of public transport users and car drivers in order to obtain a deeper understanding of travellers' attitudes towards transport and to explore perceptions of public transport users. This qualitative study highlighted some key factors influencing mode choice. In fact, the key findings indicate that the choice of transport is influenced by several factors, such as individual characteristics and lifestyle, the type of journey, the perceived service performance of each transport mode and situational variables.

Although there is general agreement that public transportation service quality is multidimensional, certain general observation can be made. For example, some have adapted and used generic models scale such as the SERVQUAL. However, significant confusion in the literature seems to exist in regards to the content, the number and the nature of the dimensions influencing consumer perceptions of public transport service (Hensheret al., 2003; Eboli \& Mazzulla, 2008; Ramseook-Munhurrun et al., 2010). 
Moreover, there were problems associated with some components of exploratory or confirmatory factor analysis, the hierarchical nature of the service quality constructs and the use of many techniques not based on customer evaluation (Yaya et al., 2012). In addition, some have used convenient sample rather than genuine user (Karatepe et al., 2005; Ladhari et al., 2009). Therefore, the scales developed in those previous studies raised some important questions that call for additional research on the topic (Parasuraman et al., 1998).

\subsection{Relationships between demographic characteristics and perceived service quality}

According to Ganesan-Lim et al., (2008) it is important to understand the relationship between the customer's perception of service quality and demographic information such as age, gender, education and income level. This information is useful for ensuring there are suitable products available for the target market (Yaya et al., 2014). For example, men and women have been shown to differ in their attitudes toward both the Internet and the traditional services. According to Stafford (1996), service quality seems more important to women than to men in the traditional bank service, although men also find certain aspects of quality to be highly important. Moreover, Mokhlis (2012) showed that male customers attached greater importance on empathy, tangibles and reliability than did female customers in retails service. Mann and Abraham (2006) study shows that social standing through expensive cars did not appear to be dependent on using them for all journeys, although this may be affected by gender. For example, whilst men aspired to more expensive cars than the women, it was only the men who regarded these cars as unsuitable for commuting. Moreover, Wardman et al., (2001) study indicates that public transport variations in values can be linked to observable and measurable characteristics, such as age, gender, journey purpose, distance travelled and group travel, whereas other sources of variation, such as those due to differences in expectations, aspirations and preferences, are less readily isolated. Furthermore, Hensher \& Prioni, (2002) study developed Service Quality Index to analyze the user preference base on 25 private bus operators and concluded that gender characteristic is a factor that influences the user preference choice related to relative utility such as treatment effect, trip purpose, and access mode. Thus, analysis of the gender perceptions of service quality may assist public transport provider in much more detailed market segmentation by delineating what service quality attributes are optimum for which groups of travelers. Therefore, it was hypothesized that

\section{H1: gender will significantly affect customers' perceptions of service quality}

Indeed, age allows a marketer to determine how wants and needs change as an individual matures (Stafford, 1996). According to Eagle, (2009) people in the same age group display similar shopping behaviour and this information is important to retailers to understand more about their market. Besides, Ganesan-Lim et al., (2008) found that age has a big influence on the perception of service quality. In addition, based on Service Quality Index, Hensher \& Prioni, (2002) study indicates that individuals on higher incomes and of more years were more likely to prefer the levels of service by the existing bus trip than by the alternative packages. This however is different based on the study by Yaya et al., (2014) who found no relationships and no differences in the various subgroups categories of age, education, and income in terms of service quality, value, and 
satisfaction in the banking setting. These contradictory results prompt calls for further investigation. In that sense, it was hypothesis that

\section{H2: Age will significantly affect customers' perceptions of service quality}

Likewise, Kotler \& Armstrong (2010) intimated that demographic characteristics are an accepted basis of segmenting markets and customers. The authors further argued that in the last sixth decade or so, there has been an increase in educated people in the United States and this leads to an increase in the demand for quality products. According to Litman (2008), one of the most important public transport benefits is that it increases education and employment participation by non-drivers. According to Samat et al., (2006) training and education has no significant impact on service quality. However, the authors argued that it may have happened because the measurement used to assess the level of training and education practiced in the service organizations were more focused on the skills not on the delivery of service itself. Thus, there is an imperative need to understand just how education affects perceptions of service quality deliver by public transport. Since, the outcome is of paramount importance to determine which elements of service quality are important to different education groups.

\section{H3: Education will significantly affect customers' perceptions of service quality}

In general, a full driving license is obtained after completing a driver's education course and passing written and practical tests. In the driving license course, students are not only thought on how to handle a car in the proper and safe manner, they are also thought the rules of the road and the laws involved as well as the basic car maintenance. According to Martin et al., (2012), actions that generate positive attitudes towards the use of public transport may increase customer perception of public transport. Such action may include introducing the concepts of sustainable mobility in the curricula of formal education and the driving license lessons. More recently, Schoettle and Sivak (2014) examined the attitudes of young adults and the potential influence of recent societal changes, including graduated licensing; changes in transportation and communication technologies; changes in the social status attached to driving and car ownership. One the study main conclusion was that young adults without a driver's license in comparison with the general population of the same age tend to have less education and higher unemployment. Drawing on that, it was anticipated that

\section{H4: Having a driving license will significantly affect customers' perceptions of service quality}

According to Martin et al., (2012) study, the psychological and social factors that influence an individual's choice of transport mode often results in a preferred use of the private vehicle over public transport. Even so, public transport systems need to become more market oriented and competitive. This requires an improvement in service quality, which can only be achieved by a clear understanding of travel behaviour and consumer needs and expectations. According to Wardman et al., (2001), public transport may be more physically demanding (e.g. it necessitates walking to a station), it may require greater cognitive effort (e.g. the need to plan and remember to leave on time) and it may involve greater affective demand (e.g. reduce comfort and enjoyment) and increased worry. On the other hand, car use bestows a feeling of control over journeys provides protection from unwanted social interaction, weather and discomfort (Mann and 
Abraham, 2006). Nonetheless, according to Hensher \& Prioni, (2002), car availability is not a factor that influences consumer public buses service quality. Therefore, it becomes essential to measure the level of service in order to identify the potential strengths and weaknesses of public transport service (Beirao and Sarsfield-Cabral, 2007). For that reason, this study anticipated that

\section{H5: Being a Car User will significant affect customers' perceptions of service quality}

Moreover, Kotler \& Armstrong (2010) intimated that demographic characteristics were an acceptable basis of segmenting customers and markets. Linked with this, Stafford (1996) it is critical to determine which elements of service quality are more important to different customers because different demographic segments might perceive different elements of service quality to be more important than others. Thus, this demonstrates the importance of determining whether or not it exist a significant difference in term of perceived service quality between each segment of the demographic characteristics. Therefore, it was hypothesis that

H6: there is significant difference in term of perceived service quality between the subcategories of gender, age, education, having driving license and car user.

\section{Methodology}

\subsection{Questionnaire and measures}

One of the explicit objectives of this study was to determine customer perception of public transport service quality and then the importance that the users place on certain improvable variables. To accomplish these objectives, we followed a multistep process. First we searched for articles published in leading academic and practitioner oriented related to public transport service. Some important factors such as tangibles, service environment and responsiveness, in addition to empathy, cleanliness etc. were identified. Nonetheless, some of those factors contained variables that were specific to retail industry or contain potential confounding features. Consequently, in-depth interviews were organized with the Girona city council management of the public bus transport. Given that in general previous researches on service quality were often based only on customers' perceptions of the service offer. Obviously, this stand-alone method often fails to capture insights from the management perspective.

After the interview, it was evidence that the quality of the public transport service is covered by many other specific factors such as the service "reliability" which reflects how good the bus transport service follows published schedules, the "aesthetics" which represents how the employees and bus are appealing. Also, the output of the management interview brought to light some other important facts such as "tangibles" which reflects how the buses are preserved and the ability to accommodate various users, including people with disabilities, prams and baggage. In addition, factor such as "information", "user comfort and security" were suggested. Finally, "convenience" that represents the extra features such as suitability and other services that enhance user comfort and enjoyment were also proposed. 
To ascertain a good content validity, we search through the literature for any items related to those relevant factors and used them as a modifier (Brady and Croning, 2001). The survey questionnaire was organized as follows: the first section started with the 22 items to assess the service quality and closed with a single question to assess overall service quality. The service quality modifier items were adapted from (Parasuraman et al., 1998; Hensheret al., 2003; Friman, 2004; Beirao and Sarsfield-Cabral, 2007; Eboli and Mazzulla., 2008; Litman, 2008). All the statements were assessed based on the 11 point Likert-type scale ranging from "Strongly Disagree" (0) to "Strongly Agree" (10). The second section sought demographic data on respondents (gender, age, education). Respondents were also asked to respond by "Yes" or "No" if they possess a driving license. In addition, respondents were asked if they were "regular", "sporadic" or "not all" car user.

\subsection{Sampling and data collection}

In order to validate the correct formulation and maximize the content validity, the questionnaire was pilot tested on a small group of 15 students and professors. A few of them suggested alternatives for some confounded wording question. In particular, they identified a total of three questions that were correctly reworded. Finally, the survey method was self-administering questionnaires distributed at various locations of the medium size city of Girona. Respondents were bus users and were selected by choosing a random starting point and choosing every fourth individual customer in succession thereafter. Respondents were primarily screened to safeguard that they had used the service within the last three months.

Data collection was completed in April 2012. After rejecting some incomplete or invalid questionnaires, the resulting sample consisted of 288 valid completed questionnaires. This figure represented $26.4 \%$ of response rate and $13 \%$ of the bus user general population. Obviously, it was necessary to check that the final data collected was undeniably a representation of the bus user population. The comparison showed that the sample accurately reflects the population in general, except for the age group $(17-24)$ which was overrepresented.

\section{Results}

\subsection{Demographic characteristics profile}

A summary of the demographic characteristics profile of the respondents in the study shows the sample was biased towards female $(63 \%)$. The sample profile also indicated that $29 \%$ attended college and primary school, $39.90 \%$ had a Bachelor's Degree and $13.70 \%$ had a Master Degree and above. On the other hand, $11.70 \%$ of respondents were attending professional training and 5.50\% did other types of education. Moreover, $51.20 \%$ of respondents were aged from 17 to 24 whereas $23.70 \%$ were aged between 25 44 and $25.10 \%$ were 45 years old and above. The sample was slightly skewed towards respondents $(56.40 \%)$ who have a driving license. Furthermore, $78.70 \%$ said they are car user and $14.10 \%$ indicate that they use a car sporadically and only $7.20 \%$ said they have never used a car.

\subsection{Assessment of the perceived service quality scale}


Arrays of Exploratory Factor Analysis (EFA) were conducted to exclude items not deemed important by respondents using normalized varimax as the rotation method. The Kaiser criteria of eigenvalues greater than 1 was utilised to determine the initial number of factors to retain (Hair et al., 1998). Careful scrutiny on the items loading were used to identify and discard items that loaded poorly (load value $<0.5$ ), cross-loaded or loaded equally in more than two factors. Closer inspection on the item loadings on their respective constructs revealed Q1 "Bus service always complies with the time scheduled", Q7 "Information at the bus stops is appropriate" and Q18 "The current price of the ticket seems right to me" loaded poorly, thus were discarded. Furthermore, a new principal components analysis was carried out using the remaining items. A check on the item loadings on their respective constructs revealed Q2 "Connections with other bus lines are adequate", Q13 "I feel safe with driving provided by the driver" and Q19 "The information on incidents such as route changes, summer time schedules etc. is appropriate" loaded in more than two factors, hence, they were deleted.

After several iterations, a final group of 16 items measuring three dimensions with a total variance of $61.44 \%$ remained. The Kaiser-Meyer-Olkin (KMO) measure was 0.92 , the Bartlett's sphericity test was 2240.11 with $\mathrm{df}=120$ and a significance of $\mathrm{P}<0.001$. According to the load of the items on their respective factors (see Table 1), the scale to measure public service transport service quality was composed of three dimensions namely "Functional Quality"; "Physical Environment quality" and "Convenience quality". The dimensions were rationally given a name that makes a good representation of all the items under the factor.

Table 1: Outer loadings for service quality measurement items

\begin{tabular}{lllll}
\hline & CFA $^{(a)}$ & \multicolumn{3}{c}{ EFA $^{(a)}$} \\
\hline Factors & Loadings t-value ( $\left.^{\text {b) }}\right)$ & 1 & 2 & 3 \\
\hline
\end{tabular}

1.Functional Quality $(\alpha=0.86 ; \mathrm{CR}=0.90 ; \mathrm{AVE}=0.59)$

Q3 Employees are friendly

$\begin{array}{lll}0.81 & 21.69 & 0.70\end{array}$

Q4 Information on the bus is adequate

$\begin{array}{lll}0.79 & 19.77 \quad 0.63\end{array}$

Q5 Employees and buses are visually appealing and neat

0.79

17.950 .66

Q16 Employees help me in case I have a problem

0.71

$10.64 \quad 0.73$

Q21 I feel safe in respect to my belongings on the bus

$0.77 \quad 19.17 \quad 0.69$

Q22 Employees (e.g. drivers, telephone, face to face etc.)

know the information needed to solve my doubts

$0.76 \quad 14.25 \quad 0.71$

2. Physical Environment Quality $(\alpha=0.84 ; \mathrm{CR}=0.88 ; \mathrm{AVE}=0.55)$

Q6 Space set for the leg is sufficient $\quad 0.67$

Q8 Buses are generally not crowded (I can often sit)

0.72

19.57

0.67

Q9Buses are accessible for the elderly, prams, disabled etc.

0.76

14.52

0.78

Q10 The safety and security measures are appropriate on the bus

$0.81 \quad 23.28$

Q12 Temperature on the bus is suitable

0.73

19.75

0.64

Q17 Buses are up to date, well equip and preserved

0.78

19.51

0.71

0.54

0.59

3. Convenience Quality $(\alpha=0.81 ; \mathrm{CR}=0.88 ; \mathrm{AVE}=0.64)$

Q11 Buses run frequently and I do not have to wait much

Q14 Information (e.g. at the station, bus stops etc.) is easy to understand

$\begin{array}{ll}0.82 & 18.25 \\ 0.80 & 21.86\end{array}$

0.80

0.63 
Q15 The bus schedules are adapted to my needs

Q20 Bus routes are adequate for my needs
0.80

21.13

0.76

$0.78 \quad 21.36$

0.65

$\begin{array}{cc}\text { Goodness of fit statistics }^{(\mathbf{c})} & \\ \chi^{2} & 236.56 \\ \mathrm{df} & 101 \\ \text { CFI } & 0.90 \\ \text { IFI } & 0.91 \\ \text { BBNFI } & 0.89 \\ \text { RMSEA } & 0.06\end{array}$

a: $\mathrm{CFA}=$ Confirmatory Factor Analysis; EFA= Exploratory Factor Analysis; Total variance extracted by the three factors equal 61.44\%; Rotation: Varimax normalized; The Kaiser-Meyer-Olkin (KMO) measure $=0.92$; Bartlett's sphericity test $=2240.11 ; \mathrm{df}=120$ with a significance of $\mathrm{p}<0.001 ; \mathrm{b}$ : all $\mathrm{t}$-value are significant at $\mathrm{P}<$ 0.001; c: CFI= Comparative Fit Index; Bollen's (IFI) fit index, BBNFI= Bentley-Bonnet Non-normed Fit Index; RMSEA= Root Mean Square Error of Approximation

Structural Equation Modelling (SEM) was used to further examine the service quality dimension measures and their reliability and validity. The demographic variables of gender, age, education and car user etc. included in the SEM were composed of all the subcategories under each construct. The best fit of the psychometric properties of the items was assessed through a comprehensive Confirmatory Factor Analysis (CFA) using Partial Least Squares (PLS). All the items retained were assessed in the same model and were restrained to load on their respective factors. Individual item was deemed valid if its load value was greater than 0.7 (Carmines and Zeller, 1979). The overall results of the CFA loadings summarized in Table 1 showed that the majority of the items exceeded the acceptable threshold. Moreover, CFA was also performed using EQS 6.1 software package to confirm the robustness of the scale. The scale fit was evaluated and the results of the robust maximum-likelihood presented in Table 1 showed the CFI was 0.90, the IFI was 0.91, the BBNFI was 0.89 and RMSEA was 0.06. Besides, the Satorra-Bentler scaled chi-square $\chi^{2}$ was 236.56 with 101 degrees of freedom. The ratio $\chi^{2} / \mathrm{df}$ was 2.3 and all standardised factor loadings were statistically significant (at $\mathrm{p}<0.000$ ). These results indicate that global fit was acceptable. The loads were all high (at a significance level of 0.05 ) and the scale was therefore shown to be an acceptable fit to the data.

Furthermore, the validity of the individual item on their corresponding factors was confirmed by their load values that met and exceeded the acceptable threshold and the tvalues of the factor loadings that were all found to be statistically significant at $\mathrm{P}<0.001$. Moreover, the internal reliability of the scales was assessed based on three indicators. Specifically the Cronbach's Alpha ( $\alpha$ ), the Composite Reliability (CR) and the Average Variance Extracted (AVE). The results presented in Table 1 indicated that the scale possessed a high internal consistency and reliability, since each for individual $\alpha$ and the CR was greater than the minimum accepted value of 0.7 (Peterson et al., 2013) and the AVE value was greater than the accepted threshold of 0.5 (Fornell and Larcker, 1981). Additionally, the convergent validity was established because all $t$-values were significant and the AVE values greater than 0.5. In addition, all the constructs pairs in the model were tested for discriminant validity following Fornell and Larcker, (1981). Discriminant validity was confirmed, since all construct pairs assessed through linear correlations were less than the square root of their corresponding AVE. Besides, discriminant validity was also confirmed by authenticating that each element included in the model represents a separate entity. The overall results presented in Table 2 further confirmed discriminant 
validity. Since, the correlation coefficients were less than 1 by an amount greater than twice their respective standard errors (Hair et al., 2011).

Table 2: Correlation between constructs

\begin{tabular}{lcccccccc}
\hline & $\mathbf{1}$ & $\mathbf{2}$ & $\mathbf{3}$ & $\mathbf{4}$ & $\mathbf{5}$ & $\mathbf{6}$ & $\mathbf{7}$ & $\mathbf{8}$ \\
\hline 1.Age & 1.00 & & & & & & & \\
2.Car User & 0.10 & 1.00 & & & & & & \\
3.Driving license & -0.08 & -0.15 & 1.00 & & & & & \\
4.Education & 0.09 & 0.01 & -0.11 & 1.00 & & & & \\
5. Functional & 0.18 & -0.07 & 0.13 & -0.14 & 1.00 & & & \\
6. Physical Environment & 0.42 & 0.02 & 0.09 & -0.12 & 0.63 & 1.00 & & \\
7.Convenience & 0.31 & 0.00 & 0.07 & -0.19 & 0.62 & 0.59 & 1.00 & \\
8.Gender & 0.14 & -0.06 & 0.03 & 0.00 & 0.00 & 0.11 & 0.07 & 1.00 \\
\hline All &
\end{tabular}

All correlations were significant $(\mathrm{P}<0.01$ at two-tailed $)$

\subsection{Causal path model assessment of factors that influence service quality}

Instead of regression analysis, the causal relationship paths between the different constructs were assessed by means of the Partial Least Square Structural Equation Modelling (PLS-SEM). PLS-SEM was deemed more reliable with this study objective. For the reason that PLS-SEM has an important capability of estimating latent variable scores as exact linear combinations of their associated manifest variables and treats them as perfect substitutes for the manifest variables (Hair et al., 2011). Moreover, PLS-SEM can achieve high levels of statistical power because it provides a flexible framework for testing a range of possible relationships between categorical independents and continuous dependents (Kline, 2011). Moreover, SEM can model all regression equations simultaneously and quantify the contribution of each predictor to the covariance structure, whereas neither the interaction of continuous variables nor the interaction terms for categorical independent variables in a regression model can do so (Kupek, 2006). The structural path representing the model's relationships was estimated by means of Partial Least Squares (PLS) with the Smart PLS 2.0 software package.

To assure that the statistically significant paths of the inner model parameter estimates were stable, the causal relationship paths were assessed based on 5000 re-samples Bootstrapping method in accordance with Hair et al., (2012). The overall results summarized in Table 3 showed that no all the hypotheses were supported $(p<.05)$. As predicted, Age was directly and positively related to customer perceived service quality as a whole (H2). Details analysis indicated that Age has the strongest influence on the perception of Physical Environment Quality, follows by Convenience and then Functional Quality.

Table 3: Hypothesis testing of the causal results

\begin{tabular}{|c|l|c|c|c|c|c|}
\hline \multicolumn{2}{|c|}{ Hypothesis } & Path & SE$^{\text {a }}$ & T-value & P-value & Conclusions \\
\hline H1a & Gender $\rightarrow$ Functional Quality & $-0,04$ & 0.04 & 0,99 & 0.322 & Rejected \\
\hline
\end{tabular}




\begin{tabular}{|l|l|c|c|c|c|c|}
\hline H1b & $\begin{array}{l}\text { Gender } \rightarrow \text { Physical and Environment } \\
\text { Quality }\end{array}$ & 0.05 & 0.04 & 1,09 & 0.277 & Rejected \\
\hline H1c & Gender $\rightarrow$ Convenience & 0.02 & 0.04 & 0,40 & 0.689 & Rejected \\
\hline H2a & Age $\rightarrow$ Functional Quality & 0,21 & 0.05 & 4,58 & 0.000 & Accepted*** \\
\hline H2b & $\begin{array}{l}\text { Age } \rightarrow \text { Physical and Environment } \\
\text { Quality }\end{array}$ & 0,44 & 0.03 & 13,86 & 0.000 & Accepted*** \\
\hline H2c & Age $\rightarrow$ Convenience & 0,34 & 0.04 & 7,67 & 0.000 & Accepted $^{* * *}$ \\
\hline H3a & Education $\rightarrow$ Functional Quality & $-0,14$ & 0.04 & 3,58 & 0.000 & Accepted*** $^{* * 1}$ \\
\hline H3b & $\begin{array}{l}\text { Education } \rightarrow \text { Physical and } \\
\text { Environment Quality }\end{array}$ & $-0,15$ & 0.04 & 3,59 & 0.000 & Accepted*** \\
\hline H3c & Education $\rightarrow$ Convenience & $-0,21$ & 0.04 & 4,64 & 0.000 & Accepted*** \\
\hline H4a & Driving license $\rightarrow$ Functional Quality & 0,12 & 0.04 & 2,71 & 0.007 & Accepted** \\
\hline H4b & $\begin{array}{l}\text { Driving license } \rightarrow \text { Physical and } \\
\text { Environment Quality }\end{array}$ & 0,11 & 0.04 & 2,70 & 0.007 & Accepted** \\
\hline H4c & Driving license $\rightarrow$ Convenience & 0,07 & 0.05 & 1,54 & 0.124 & Rejected \\
\hline H5a & Car User $\rightarrow$ Functional Quality & $-0,07$ & 0.05 & 1,48 & 0.140 & Rejected \\
\hline H5b & $\begin{array}{l}\text { Car User } \rightarrow \text { Physical and Environment } \\
\text { Quality }\end{array}$ & 0.00 & 0.04 & 0,07 & 0.944 & Rejected \\
\hline H5c & Car User $\rightarrow$ Convenience & $-0,02$ & 0.04 & 0,60 & 0.549 & Rejected \\
\hline
\end{tabular}

In the same vein, the study results also indicated that owning a Driving License is a factor that influences the customer perceived service quality (H4). Possessing a Driving License influences equally customer perception of Functional (H4a), Physical Environment Quality (H4b). Nonetheless, owning a Driving License has no influences on perception of Convenience (H4c). Contrary to our prediction, being a Car User has no effects neither on overall service quality nor on any of the factors associated (H5). Moreover, the results show Education was strongly and negatively related to customer perceived overall quality $(\mathrm{H} 3)$ with Convenience $(\mathrm{H} 3 \mathrm{c})$ as the strongest factor follows by the Environmental (H3b) and Functional dimension (H3a). In contrast, the proposed relationships between Gender and all the dependent variables of service quality were not supported (H1).

In addition, independently of the SEM results, the sample was also subjected to the Mann-Whitney $U$ and Kruskall-Wallis tests to detect if there were any mean differences among the subcategories. These choices were motivated by the fact that some of the data were slightly off-centre; hence, they were not normally distributed. The overall results summarized in Table 4 indicate significant mean differences between the subcategories of education. The results reveal an interesting finding. Customers with high school follow by college education appeared to have the highest perception on each of the three components of quality as well as on the overall service quality. In contrast, those with Professional Training follow by University Degree and above education rated lowest their perception of physical environment, follows by convenience and then functional Quality.

Table 4: Kruskal-Wallis results with the grouping variable of Education

\begin{tabular}{|l|l|l|l|}
\hline & Functional & Physical Environment & Convenience \\
\hline
\end{tabular}




\begin{tabular}{|c|c|c|c|c|c|c|}
\hline & Mean & SD & Mean & SD & Mean & SD \\
\hline High School & 8,79 & 0,93 & 8,49 & 1,37 & 8,74 & 1,19 \\
\hline College & 8,25 & 1,47 & 7,53 & 1,66 & 8,02 & 1,64 \\
\hline $\begin{array}{l}\text { Bachelor's } \\
\text { Degree }\end{array}$ & 7,98 & 1,35 & 6,63 & 1,70 & 6,94 & 1,81 \\
\hline $\begin{array}{l}\text { Professional } \\
\text { Training }\end{array}$ & 7,47 & 2,01 & 7,15 & 1,52 & 6,99 & 2,03 \\
\hline $\begin{array}{l}\text { Master's Degree } \\
\text { and above }\end{array}$ & 7,79 & 1,53 & 7,00 & 1,61 & 6,98 & 1,77 \\
\hline Others & 8,42 & 1,13 & 7,86 & 1,23 & 7,98 & 2,56 \\
\hline Sig. & \multicolumn{2}{|c|}{0,005} & \multicolumn{2}{|c|}{0,000} & \multicolumn{2}{|c|}{0,000} \\
\hline
\end{tabular}

The overall results presented in Table 5 also indicated that age was proved to be a discriminating variable on all the three factors of perceived service quality. An inspection of the factor score means reveals there is a consistent linear trend across the dimensions. The mean importance rating for those aged 17-24 is lower than any other subcategory group. Besides, convenience was the factor that those aged 17-24 rated lowest, follows by the physical environment and then functional quality. Nevertheless, the importance rating for those aged 45 and above was the highest across all the dimensions.

Table 5: Kruskal-Wallis results with the grouping variable of Age

\begin{tabular}{|l|c|c|c|c|c|c|}
\hline & \multicolumn{2}{|c|}{ Functional } & \multicolumn{2}{c|}{$\begin{array}{c}\text { Physical } \\
\text { Environment }\end{array}$} & \multicolumn{2}{c|}{ Convenience } \\
\hline & Mean & SD & Mean & SD & Mean & SD \\
\hline $17-24$ & 7,86 & 1,40 & 6,49 & 1,55 & 6,95 & 1,72 \\
\hline $25-44$ & 8,06 & 1,51 & 7,66 & 1,60 & 7,41 & 1,94 \\
\hline $45-54$ & 8,42 & 1,11 & 7,87 & 1,40 & 8,20 & 1,41 \\
\hline 55 and above & 8,44 & 1,68 & 8,21 & 1,54 & 8,38 & 2,03 \\
\hline Sig. & \multicolumn{3}{|c|}{$\mathbf{0 , 0 0 4}$} & \multicolumn{3}{|c|}{$\mathbf{0 , 0 0 0}$} \\
\hline
\end{tabular}

Contrary to our predictions, the overall results presented in Table 6 and 7 indicate that there was no significant difference of perceived service quality between the subcategories of Male and Female as well as between owing and not a driving license. In the same vein, the overall results presented in Table 8 also indicate no significant difference of perception of service quality between those using a car regularly, sporadically and not all.

Table 6: U de Mann-Whitney test of significance between Male and Female

\begin{tabular}{|c|c|c|c|c|c|c|}
\hline & \multicolumn{2}{|c|}{ Functional } & \multicolumn{2}{|c|}{ Physical Environment } & \multicolumn{2}{|c|}{ Convenience } \\
\hline & Mean & SD & Mean & SD & Mean & SD \\
\hline Male & 8,07 & 1,11 & 6,88 & 1,61 & 7,20 & 1,84 \\
\hline Female & 8,05 & 1,58 & 7,28 & 1,73 & 7,48 & 1,91 \\
\hline Sig. & \multicolumn{2}{|c|}{0,55} & \multicolumn{2}{|c|}{$\mathbf{0 , 0 8}$} & \multicolumn{2}{|c|}{0,23} \\
\hline
\end{tabular}

Table 7: U de Mann-Whitney test with the grouping variable of owing a driving license 


\begin{tabular}{|l|c|r|r|r|r|r|}
\hline & \multicolumn{2}{|c|}{ Functional } & \multicolumn{2}{c|}{ Physical Environment } & \multicolumn{2}{c|}{ Convenience } \\
\hline & Mean & \multicolumn{1}{|c|}{ SD } & Mean & \multicolumn{1}{c|}{ SD } & \multicolumn{1}{c|}{ Mean } & \multicolumn{1}{c|}{ SD } \\
\hline Yes & 7,90 & 1,58 & 7,05 & 1,68 & 7,28 & 1,83 \\
\hline No & 8,25 & 1,30 & 7,34 & 1,73 & 7,57 & 1,96 \\
\hline \multicolumn{1}{|c|}{ Sig. } & \multicolumn{2}{|c|}{$\mathbf{0 , 0 9}$} & \multicolumn{2}{|c|}{$\mathbf{0 , 1 6}$} & \multicolumn{2}{|c|}{$\mathbf{0 , 1 6}$} \\
\hline
\end{tabular}

Table 8: Kruskal-Wallis results with the grouping variable of Car User

\begin{tabular}{|l|c|c|c|c|c|c|}
\hline & \multicolumn{2}{|c|}{ Functional } & \multicolumn{2}{c|}{$\begin{array}{c}\text { Physical } \\
\text { Environment }\end{array}$} & \multicolumn{2}{c|}{ Convenience } \\
\hline & Mean & SD & Mean & SD & Mean & SD \\
\hline Yes & 8,13 & 1,38 & 7,15 & 1,78 & 7,41 & 1,90 \\
\hline No & 7,39 & 2,20 & 7,51 & 1,53 & 7,36 & 2,25 \\
\hline Sporadically & 7,98 & 1,46 & 7,17 & 1,34 & 7,37 & 1,65 \\
\hline Sig. & \multicolumn{2}{|c|}{$\mathbf{0 , 3 8 0}$} & \multicolumn{2}{c|}{$\mathbf{0 , 7 4 8}$} & \multicolumn{2}{c|}{$\mathbf{0 , 8 8 2}$} \\
\hline
\end{tabular}

\section{Conclusions and management implications}

Nowadays, there are several different forms of public transportation services available including buses, various forms of train systems that provide short or long distance travel, ferries, subways etc. The benefits of public transportation impact each and every one. Not just in terms of environment benefice as it cuts down on the amount of the cars on the road and hence reduces the emission of carbon dioxide, it also contributes to the reduction of air pollution, noise and traffic congestion (Teicher et al., 2002; Friman, 2004; Eboli and Mazzulla., 2010; Cipriani et al., 2012). In social terms, public transportation ensures that all members of the society including people with disabilities, children etc. are able to freely move around without any restriction. In addition, it provides basic mobility, such as access to medical services, essential shopping, education or employment opportunities (Litman, 2008). Thus, providing a superior service quality in public transport service is one of the crucial aspects to take into account while talking about citizen welfare.

This study adopts a mixed method approach to understand and conceptualize scales to assess bus public transport service. By combining management interviews and the existing literature to gain insights that may have been missed by previous researches which have often used the stand-alone method based on customers perspectives. The overall, results indicated that Functional, Physical Environmental and Convenience represent the underlying dimensions of customer perceived service quality in public transport setting. Obviously, Functional Quality is composed of items related to aesthetic, assurance, empathy and responsiveness; while Physical Environmental quality is composed of items related to atmosphere, comfort, ease of access, safety and security. Finally, the Convenience Quality was composed of items related to reliability, efficiency and suitability.

Thereafter, this study seeks to comprehend the fundamental demographic characteristics that may influence the perception of service quality dimensions. The overall results showed that age and owning a driving license are factors that directly and positively affect all the dimensions of customer perceived service quality. This is consistent with Schoettle and Sivak (2014) who argued that young driver licensing in the 
USA preferred to use public transportation because maintaining a vehicle is too expensive. The output result is consistent with (Stafford, 1996; Ganesan-Lim et al., 2008) who also found age has a big influence on the perception of service quality.

On the other hand, Education directly and negatively influences the construct of overall service quality and all its components. This was consistent with the study of Schoettle and Sivak (2014) who found that $37 \%$ of students said they were too busy or do not have enough time to get a driver's license. In contrast, the proposed relationships of both Gender and being a car user on service quality were not supported. This was in accordance with Yaya et al., (2014) who also found gender not to be related to service quality in the banking sector. However, the results were contrary to Mann and Abraham (2006) who indicated that there could be a gender difference in the salience of car ownership and driving identity. Moreover, across the three dimensions of customers perceived service quality the means decrease considerably as age decreases. The immediate consequence was that, younger commuters appear to have lower perceptions of the service quality attributes as compared to adults. This result is consistent with Hensher \& Prioni, (2002) who also found that it is the younger and those on lower incomes who see a greater need for improved bus service quality.

Furthermore, the behaviour difference between the subgroup categories showed customers with high school follow by college education alleged the most important factors to be taken into account while developing public transport service must be the functional quality, follows by the physical environmental and the convenience quality. In contrast, the mean score of those with Professional Training education follows by University Degree and above were very low across all the dimensions of service quality. The current study does suggest that people with university education and above may be a better audience for advertising appeals focusing on one of these three significant dimensions of service quality.

Indeed, the proposed customer perceived service quality can help public transport service management to identify which service quality factors are considered the most important by their customers. It can also be used to help prioritize future quality of service improvement initiatives, measure the degree of success of past initiatives and track changes in service quality over time. Factors, such as age, education and owning a driving license can be used for monitoring, evaluating, and implementing improvements in service quality offer.

In addition, service providers can offer a targeted service based on the importance each subcategory group according to the degree of importance given to each dimension of service quality. For example, a development of sustainable mobility workshops with information related to low service charge may improve customer consumption of public transport. Besides, it is important to start promoting the importance of public transport in schools and college with the end means that ensure the acquisition and knowledge on how to properly use all possibilities offered by the public transport. Moreover, promotional efforts related to the convenience quality items might be highly effective for those aged 17-24. Targeted services, such as express commuter buses, and services to students' special events may have a significant difference in the students' perception of service quality. Introduction of a sustainable bus with no/limited CO2 emission in the curriculum, bus comfort improvements such as more and better seats may improve perception of service quality for people with higher education. All in all, it is imperative for public 
transport service managers to be sensitive to the different demographic characteristic segments when developing corresponding marketing and promotion strategies.

Even though findings of this study provide initial direction in assessing service quality, some limitations must be acknowledged. The sample split into the subgroups of demographic categories shows only about $20 \%$ were "No" and "occasional" car user. Moreover, there was a slight gender bias and the aged group 17-24 was overrepresented. this could be due to the time-of-day, place-of-location, or, alternatively, that this group was more interested in responding and did not decline as often as other agegroups.Therefore, future research may use a larger and balance sample size. Another limitation was that the study was confined to the bus service industry, in one country and a medium size city which makes the generalizing the results risky. A replication of this study in different country and other transportation public service such as subway and long distance train service would therefore be desirable. Further, the response rate of this study was very low (26.4\%). The extant literature indicates that a low response rate can creates sampling bias if the nonresponse is unequal among the participants regarding exposure and/or outcome. Therefore, we recommend replication of this research to be done with higher response rates in order to assure more accurate survey results.

\section{References}

Beirão, G., \& Sarsfield Cabral, J. A. (2007). Understanding attitudes towards public transport and private car: A qualitative study. Transport policy, 14(6), 478-489.

Brady, Michael K. and J. Joseph Cronin (2001), "Some New Thoughts on Conceptualizing Perceived Service Quality: A Hierarchical Approach," Journal of Marketing, 65 (July), 34-49.

Carmines, E. G., \& Zeller, R. A. (Eds.). (1979). Reliability and validity assessment (Vol. 17). Sage.

Cipriani, E., Gori, S., \& Petrelli, M. (2012). A bus network design procedure with elastic demand for large urban areas. Public Transport, 4(1), 57-76.

Eboli, L., \& Mazzulla, G.(2008) A stated preference experiment for measuring service quality in public transport. Transportation Planning and Technology, 31(5), 509-523.

Fornell, C., \& Larcker, D.F. (1981). "Evaluating structural equation models with unobservable variables and measurement error" Journal of Marketing Research, 28(1), 39-50.

Friman, Margareta. (2004), "Implementing quality improvements in public transport." Journal of Public Transportation 7.4

Grönroos, C. (1984) "A service quality model and its marketing implications." European Journal of Marketing 18 (4), 36-44.

Hair, J. F., Ringle, C. M., \& Sarstedt, M. (2011). "PLS-SEM: Indeed a silver bullet." Journal of Marketing Theory and Practice, 19(2), 139-151.

Hair, J. F., Sarstedt, M., Ringle, C, M., \& Mena, J. A. (2012). "An assessment of the use of partial least squares structural equation modeling in marketing research". Journal of the Academy of Marketing Science, Iss 40, pp 414-433

Hair, J.F., Anderson, R.E., Tatham, R.L., \& Black, W.C. (1998). "Multivariate data analysis (5thed.)". Upper Saddle River, NJ: Prentice Hall International. Inc.

Hensher, D. A., Stopher, P., \& Bullock, P. (2003). Service quality-developing a service quality index in the provision of commercial bus contracts.Transportation Research Part A: Policy and Practice, 37(6), 499-517. 
Hensher, D. A., \& Prioni, P. (2002). A service quality index for area-wide contract performance assessment. Journal of Transport Economics and Policy (JTEP), 36(1), 93-113.

Hu, K. C., \& Jen, W. (2006). Passengers' perceived service quality of city buses in Taipei: scale development and measurement. Transport Reviews, 26(5), 645-662.

Karatepe, O. M., Yavas, U., \& Babakus, E. (2005). "Measuring service quality of banks: scale development and validation." Journal of Retailing and Consumer Services, 12(5), 373-383.

Kline, R. B. (2011). Principles and practice of structural equation modeling. Guilford press.

Kupek, E. (2006). Beyond logistic regression: structural equations modelling for binary variables and its application to investigating unobserved confounders. BMC Medical Research Methodology, 6(1), 13.

Ladhari, R. (2009). "A review of twenty years of SERVQUAL research" International Journall of Quality and Service Sciences, 1(2), 172-198.

Litman Todd (2008), "Valuing Transit Service Quality Improvements," Journal of Public Transportation, Vol. 11, No. 2, pp. 43-64

Mann, E., \& Abraham, C. (2006). The role of affect in UK commuters' travel mode choices: An interpretative phenomenological analysis. British Journal of Psychology, 97(2), 155-176.

Marimon F., Yaya P.L.H; Casadesus M. (2012), "Impact of e-Quality and Service Recovery on Loyalty: A Study of e-Banking in Spain" Total Quality Management and Business Excellence, Volume 23, Numbers 7-8, pp. 769-787(19)

Nutt, P. C. (2006). Comparing public and private sector decision-making practices. Journal of Public Administration Research and Theory, 16(2), 289-318.

Parasuraman, A., Zeithaml, V.A., Berry L.L (1988), “ SERVQUAL:A Mulitple-Item Scale for MMeasuring Consumers Perceptions of Service Quality," Journal of Retailing, 64(1), 12-37

Peterson, Robert A.; Kim, Yeolib (2013). "On the relationship between coefficient alpha and composite reliability" Journal of Applied Psychology, Vol 98(1), Jan 2013, 194-198.

Ramseook-Munhurrun, Prabha, Soolakshna D. Lukea-Bhiwajee, and Perunjodi Naidoo. (2010). "Service quality in the public service." International Journal of Management \& Marketing Research (IJMMR) 3.1

Samat, N., Ramayah, T., \& Saad, N. M. (2006). "TQM practices, service quality, and market orientation: some empirical evidence from a developing country". Management Research News, 29(11), 713-728.

Schoettle, B., \& Sivak, M. (2014). "The reasons for the recent decline in young driver licensing in the United States". Traffic injury prevention, 15(1), 6-9.

Stafford, M. R. (1996). "Demographic discriminators of service quality in the banking industry." journal of services marketing, 10(4), 6-22.

Wardman, M., Hine, J., \& Stradling, S. G. (2001). Interchange and travel choice. Edinburgh: Scottish Executive Central Research Unit.

Yaya P.L.H, Marimon F., Casadesus M. (2012) "Assessing e-service quality: the current state of E-S-QUAL", Total Quality Management \& Business Excellence, Volume 23, Issue 12, pp. 1363-1378.

Yaya P.L.H, Marimon F., Casadesus M. (2013) "The contest determinant of delight and disappointment: the case study of online banking" Total Quality Management and Business Excellence, Volume 24, Issue 12, pp. 1376-1389. 
Yaya P.L.H, Marimon F., Casadesus M. (2014) "Customer Satisfaction and the Role of Demographic Characteristics in Online Banking." In Evaluating Websites and Web Services: Interdisciplinary Perspectives on User Satisfaction, IGI Global, pp. 138154

Yaya P.L.H, Marimon F., Casadesus M., (2011) “Customer's loyalty and perception of ISO 9001 in online banking”, Industrial Management \& Data Systems, Vol. 111 Iss: 8, pp. $1194-1213$. 